Research Paper

\title{
Mechanism of suppressors of cytokine signaling 1 inhibition of epithelial-mesenchymal transition signaling through ROS regulation in colon cancer cells: suppression of Src leading to thioredoxin up-regulation
}

\author{
Sung-Hoon Jung ${ }^{1}$, Su-Min Kim ${ }^{1}$, Choong-Eun Lee ${ }^{1}$ \\ ${ }^{1}$ Department of Biological Science, College of Science, Sungkyunkwan University, Suwon 440-746, Korea \\ Correspondence to: Choong-Eun Lee, email: celee@skku.edu \\ Keywords: suppressors of cytokine signaling, reactive oxygen species, Src, thioredoxin, EMT signaling \\ Received: February 26, 2016 \\ Accepted: August 09, 2016 \\ Published: August 23, 2016
}

\section{ABSTRACT}

Reactive oxygen species (ROS) participate in malignant progression of cancers including epithelial-mesenchymal transition (EMT). We have investigated the role of suppressors of cytokine signaling (SOCS)1 as an inhibitor of ROS-induced EMT using colon cancer cell lines transduced with SOCS1 and shSOCS1. Hydrogen peroxide treatment induced EMT features such as elevation of vimentin and Snail with a corresponding reduction of E-cadherin. The EMT markers are significantly decreased upon SOCS1 over-expression while increased under SOCS1 knock-down. SOCS1 inhibited ROS signaling pathways associated with EMT such as Src, Jak, and p65. Of note, strong up-regulation of Src activity in SOCS1-ablated cells was responsible for the elevated signaling leading to EMT, as shSrc or Src inhibitor abolished the shSOCS1induced promotion of EMT response. Suppression of ROS-inducible EMT markers and invasion in SOCS1 over-expressing cells correlated with significantly low intracellular ROS levels in these cells. Analysis of antioxidant enzymes in SOCS1-transduced cells revealed a selective up-regulation of thioredoxin ( $\operatorname{Trx} 1)$, while thioredoxin ablation restored ROS levels and the associated EMT markers. As a mechanism of thioredoxin up-regulation by SOCS1, inhibition of Src activity promoting nuclear translocation of Nrf-2 is proposed. Taken together, our data strongly indicate that SOCS1 antagonizes EMT by suppressing Src activity, leading to thioredoxin expression and downregulation of ROS levels in colon cancer cells.

\section{INTRODUCTION}

Reactive oxygen species (ROS) have been implicated during initiation, promotion, and malignant progression for cancers of the breast, liver, and colon [1-3]. ROS is also shown to participate in epithelial - mesenchyme transition (EMT) [4-5]. EMT causes epithelial cells to lose their polarity and intercellular adhesion, and then to gain fibroblast-like and invasive properties to become cells with mesenchymal features $[6,7]$. Transcription factors such as Snail, Twist, and SIP1 activate EMT by regulating expression of genes involved in cell adhesion and migration [8-10]. EMT is thus considered critical for tumor cell invasion to acquire malignant phenotype [11].

It has been reported that cancer cells under hypoxia exhibited increased intracellular ROS levels and finally progressed to EMT, the process of which was blocked by an anti-oxidant N-acetyl cysteine (NAC) [12]. Both MMP3 and MMP9 are implicated as inducers of ROS leading to EMT in breast and colon cancer cells [13, 14]. In addition, NADPH oxidase (Nox) 1-induced ROS generation appears responsible for EMT and invasion of melanoma cells [15]. While these findings provide insights for the mechanism of ROS generation and ROS-induced EMT process in diverse tumor cells, strategies targeting ROS signal pathways to prevent EMT have not been extensively investigated.

Proto-oncogene Src (c-Src) has been widely reported for transformation, proliferation and metastatic process of diverse tumors [16-18]. Src is shown to induce cell motility and invasion through p38/Akt pathways in breast cancers and glioma [16]. For colon cancer models, deregulation of Csk, a negative regulator of Src induced invasion [17], and the Src signaling pathway was identified as the target of 
the metastatic suppressor NDGR1 [18]. Through its ability to activate Nox 1 in Rac-dependent mechanism, Src may contribute to the ROS-induced EMT process and invasion of colon cancer cells [19].

Suppressors of cytokine signaling (SOCS), initially found as inhibitors of JAK/STAT pathways, have emerged as multi-functional proteins governing cell growth and differentiation $[20,21]$. The tumor suppressive function of SOCS has been demonstrated through the blockade of growth signaling pathways which utilize both receptor and non-receptor tyrosine kinases including EGFR, Mek, Jak, and Src family proteins [22-25]. In breast and hepatic carcinoma cells, expression levels of SOCS1 are down-regulated by the promoter DNA methylation, the reversal of which resulted in the induction of SOCS1 and anti-growth properties $[26,27]$. In addition, SOCS may exert tumor suppressive effects by promoting the action of p53 and p21. SOCS1 is shown to enhance p53 activation through binding with p53 [28], while SOCS3 up-regulates p21 expression and cell cycle arrest upon DNA damage [29]. On the other hand, several studies suggested protumor functions of SOCS1 [30, 31]. Upon the analysis of gene expression data sets of human colorectal cancer specimens, SOCS1 expression is found elevated in tumors than normal epithelium. In line with this observation, the over-expression of SOCS1 promoted cell growth and resistance to death stimuli of colon cancer cells [30].

In fact, both pro-apoptotic and anti-apoptotic functions of SOCS1 have been noted depending on the tumor cell types and apoptotic triggers. For example, it has been reported that SOCS1 promoted Fas-induced apoptosis by $\mathrm{NF}-\kappa \mathrm{B}$ down-regulation [32] whereas it inhibited TNF- $\alpha$-induced apoptosis by suppression of Jaks in Jurkat T cells [33]. We have observed that during the ROS-mediated apoptosis of immune cells SOCS1 expression was induced by ROS, and SOCS1 over-expression led to the inhibition of oxidant-induced apoptosis. As a mechanism to inhibit ROS signaling, SOCS1 protected protein tyrosine phosphatases (PTP) from inactivation by ROS attack [33].

Based on such anti-oxidant effect of SOCS1 we have hypothesized that SOCS1 may prevent ROSinduced EMT and invasive property of cancer cells, and sought to investigate molecular mechanisms involved. Employing colon cancer cell lines transduced with SOCS1 or shSOCS1, we have obtained data indicating that SOCS1 suppresses intracellular ROS levels and EMT signaling through the inhibition of Src activity. The Src inhibition by SOCS1 led to up-regulation of nuclear Nrf-2 and expression of thioredoxin (Trx1), a key antioxidant defense enzyme to down-regulate intracellular ROS. Reduced ROS levels and attenuated EMT signal caused by Src suppression in SOCS1-transduced cells were recovered by thioredoxin ablation, suggesting that thioredoxin and Src form a novel regulatory loop for the anti-EMT function of SOCS1 through ROS.

\section{RESULTS}

\section{Induction of SOCS1 and changes in EMT markers by hydrogen peroxide}

Since ROS signaling is important in the induction of the malignant growth of tumors through EMT, the ROS inhibiting action of SOCS1 to suppress EMT has been a subject of interest. In order to investigate the role of SOCS1 in tumor cell response to ROS, induction of SOCS1 expression by hydrogen peroxide, a direct source of ROS, was first examined. In p53+/+ HCT116 colon cancer cell lines, SOCS1 is induced time- and dosedependent manners upon $\mathrm{H}_{2} \mathrm{O}_{2}$ stimulation, suggesting a potential regulatory role of SOCS1 during the cellular response to ROS in these cells (Figure 1A and 1B). Under the conditions applied for SOCS1 induction, significant changes in expression levels of EMT markers were observed. Up-regulation of mesenchymal markers, vimentin and Snail with simultaneous down-regulation of epithelial marker E-cadherin was obtained at $200 \mathrm{uM} \mathrm{H}_{2} \mathrm{O}_{2}$ treatment for $2 \mathrm{~h}$ (Figure 1A). These conditions were thus considered optimal for the induction of EMT and used for the experiments followed for the parental HCT116 cells.

The EMT marker induction by $\mathrm{H}_{2} \mathrm{O}_{2}$ was observed in the anti-oxidant NAC-sensitive manner both in HCT116(p53 wt) and HCT116(p53 null) as well as HT29(p53 mt) colon cancer cells, indicating that EMT induction by ROS occurred independent of p53 activity in colon cancer cell lines (Figure 1C). Elevation of cellular ROS levels by $\mathrm{H}_{2} \mathrm{O}_{2}$ treatment and its abrogation upon pre-incubation with NAC also exhibited similar patterns in different colon cancer cells, which supported the above notion (Figure 1D). In p53+/+ HCT116 cells, SOCS1 induction was evident from $4 \mathrm{~h}$, kinetically following the maximal induction of EMT markers seen at $2 \mathrm{~h}$ (Figure 1A). Likewise, higher levels of SOCS1 induced upon $300 \sim 500 \mu \mathrm{M} \mathrm{H}_{2} \mathrm{O}_{2}$ treatment were seen with a slightly reduced EMT response as compared with the maximal EMT at $200 \mu \mathrm{M} \mathrm{H}_{2} \mathrm{O}_{2}$ (Figure 1B). This suggests an antiEMT function of SOCS1 as a part of the anti-oxidant response.

\section{ROS-induced EMT signaling and anti-EMT effect of SOCS1 through Src regulation}

To investigate the role of SOCS1 in the regulation of ROS-induced EMT, HCT116/p53 wt cells stably overexpressing or knock-down for SOCS1 were established using transduction of HA-SOCS1 or sh-SOCS1 genes as described [33]. As shown in immunoblots and densitometric analysis data (Figure 2A and 2B) the mock cells responded in a manner similar to the parental cell line upon treatment with $\mathrm{H}_{2} \mathrm{O}_{2}$ with induction of vimentin and Snail with decrease in E-cadherin (vimentin and Snail induction by 1.5 to 2.0 fold; E-cadherin reduction by 2 
to 3 fold). SOCS1-transduced cells exhibited low levels of EMT markers independent of $\mathrm{H}_{2} \mathrm{O}_{2}$ or NAC treatment. On the contrary, sh-SOCS1 cells were found to have elevated EMT markers. Confocal analysis confirmed the increased expression of vimentin and reduced expression of E-cadherin by $\mathrm{H}_{2} \mathrm{O}_{2}$, which were reversed by NAC treatment in mock cells (Figure 2C, upper left panel). Induction of Twist expression, a metastasis-promoting transcription factor, was observed by $\mathrm{H}_{2} \mathrm{O}_{2}$ treatment in mock cells (Figure 2C, lower left panel). On the other hand, in SOCS1 over-expressing cells, the expression of vimentin and Twist was notably reduced while E-cadherin levels elevated (Figure 2C, right panels). These data strongly suggest that ROS signal induces EMT and that SOCS1 has an anti-EMT effect in colon cancer cells.

Next, in order to delineate the mechanism of SOCS1 inhibition on EMT, ROS-induced signaling pathways leading to EMT were first examined. Jak and Src are of particular interest, since Jak is a classical target of SOCS1 [21] and Src is a potential regulator of EMT [17, 18, 34]. Both Jak1 and Src activation was noted upon exposure to $\mathrm{H}_{2} \mathrm{O}_{2}$ from 10 to $60 \mathrm{~min}$ (Figure 3A). While Jak inhibitor AG490 slightly suppressed Src activation, Src inhibitor PP1 strongly blocked both Jak1 and Src activation as shown by reduced tyrosine phosphorylation together with decreased expression of downstream molecules for
EMT including p65 and Snail (Figure 3B and 3C). In shSOCS1 cells elevated pY-Src and pY-Jak1 were noted, which were both subject to a complete inhibition by PP1. Only a partial inhibition of pY-Src was obtained by AG490 treatment. Still both AG490 and NAC suppressed shSOCS1-induced increase of Snail and nuclear p65, while restoring E-cadherin levels. The result suggests that shSOCS1-induced promotion of EMT signal involves Jak and Src activated by ROS (Figure 3D). SOCS1 inhibition of Jak is known to involve molecular interaction of SOCS1 with tyrosine phosphorylated Jak $[33,35]$. SOCS1 also has been reported to bind other phosphorylated substrates, leading to SOCS-box mediated degradation $[36,37]$. Hence, in order to find out whether the observed SOCS1 inhibition of Src involves interaction of the two molecules, co-immunoprecipitation assay was performed. In HCT116 cells transduced with SOCS1, the c-Src antibody immunoprecipitates contained SOCS1 along with Src (Figure 3E). The result suggests that SOCS1 binds with Src, which may serve as a mechanism of the SOCS1 inhibition of Src and the subsequent EMT signaling.

\section{Anti-EMT function of SOCS1 through ROS down-regulation is mediated by thioredoxin}

To identify the role of intracellular ROS signal during the hydrogen peroxide-induced EMT in HCT116
A

\begin{tabular}{|c|c|c|c|c|c|}
\hline $\mathrm{H}_{2} \mathrm{O}_{2}(\mathrm{~h})$ & 0 & 1 & 2 & 4 & 8 \\
\hline E-Cad & 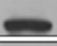 & - & - & $=$ & - \\
\hline Vimentin & - & - & - & - & - \\
\hline Snail & $\cdots$ & - & - & - & 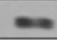 \\
\hline SOCS1 & & $=$ & - & - & - \\
\hline$\beta$-Actin & $=$ & - & 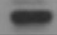 & 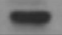 & $\infty$ \\
\hline
\end{tabular}

B

\begin{tabular}{|l|l|l|l|l|l|}
\hline $\mathrm{H}_{2} \mathrm{O}_{2}(\mu \mathrm{M})$ & 0 & 100 & 200 & 300 & 500 \\
\hline & \\
E-Cad & \\
Vimentin & \\
Snail & \\
SOCS1 & \\
$\beta$-Actin & \\
\hline
\end{tabular}

C

\begin{tabular}{|c|c|c|c|}
\hline $\mathrm{H}_{2} \mathrm{O}_{2}$ & - & + & + \\
\hline NAC & - & - & + \\
\hline \multirow[t]{2}{*}{ Vimentin } & - & - & - \\
\hline & 1.0 & 1.6 & 0.8 \\
\hline \multirow{2}{*}{ Slug } & W & $z$ & \\
\hline & 1.0 & 3.1 & 1.4 \\
\hline \multirow[t]{2}{*}{ Snail } & 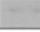 & - & - \\
\hline & 1.0 & 4.1 & 2.1 \\
\hline \multirow[t]{2}{*}{ E-Cad } & - & $\ldots$ & - \\
\hline & 1.0 & 0.5 & 1.2 \\
\hline
\end{tabular}

$<$ HCT116 p53 -/->

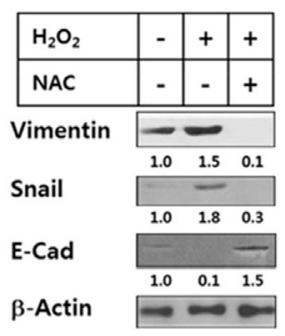

$<$ HT29>

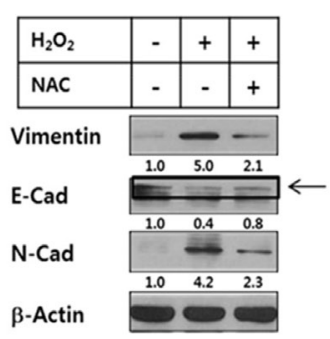

D

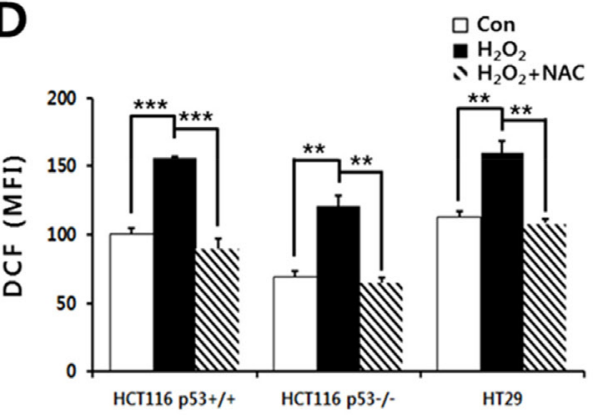

Figure 1: Regulation of EMT markers and SOCS1 expression by $\mathrm{H}_{2} \mathrm{O}_{2}$ and effects of NAC on $\mathrm{H}_{2} \mathrm{O}_{2}$-induced ROS and EMT markers in colon cancer cell lines. HCT116 p53 +/+ cells were treated with $\mathrm{H}_{2} \mathrm{O}_{2}$ at $200 \mu \mathrm{M}$ for different durations A., and for $2 \mathrm{~h}$ at increasing doses B., which were then subjected to the immunoblot analysis for SOCS1 and EMT markers. HCT116 p53+/+, HCT116 p53-/-, and HT29(p53mt) colon cancer cell lines were treated with $\mathrm{H}_{2} \mathrm{O}_{2}(200 \mu \mathrm{M}, 2 \mathrm{~h})$ with or without pretreatment of NAC for $1 \mathrm{~h}$ at $10 \mathrm{mM}$, after which EMT marker expressions were analyzed $\mathbf{C}$. The ROS levels in these cells were determined at 30 min post $\mathrm{H}_{2} \mathrm{O}_{2}$ treatment D. 
colon cancer cells, kinetics of changes in intracellular ROS levels were analyzed. Upon $\mathrm{H}_{2} \mathrm{O}_{2}$ treatment, ROS generation was detected from $10 \mathrm{~min}$ and peaked at 30 min which is decreased thereafter. ROS scavenging drugs NAC as well as DPI abrogated the ROS levels induced by hydrogen peroxide (Figure 4A and Supplementary Figure S1). Since cells transduced with SOCS1 exhibited reduced expression of EMT markers resembling the effect of anti-oxidant, we have examined the effect of SOCS1 or shSOCS1 on the intracellular ROS levels. HA and sh mock cells responded to hydrogen peroxide with a peak of ROS in 10 to $30 \mathrm{~min}$, in a similar manner to the parental HCT 116 cells. However, intracellular ROS levels were kept significantly low in SOCS1-transduced cells, whereas substantially high in SOCS1-ablated cells (Figure 4B and Figure 4C). Both cells are resistant to changes in ROS levels upon extrinsic oxidant stimulation, which correlates with rather consistent expression of EMT markers. They are observed at low levels upon SOCS1 over-expression and high levels upon SOCS1 knockdown independent of $\mathrm{H}_{2} \mathrm{O}_{2}$ treatment (Figure 2B). To investigate the mechanism by which ROS dysregulation occurs by SOCS1, the induction of anti-oxidant enzymes was analyzed. As shown in Figure 5A, hydrogen peroxide treatment at concentrations used for EMT induction leads to transient up-regulation of thioredoxin (Trx1) from 1 to $4 \mathrm{~h}$, but not of the other anti-oxidant enzymes, such as peroxiredoxin (Prx), thioredoxin reductase (TrxR1), and superoxide dismutase (SOD1). In SOCS1 over-expressing cells, thioredoxin level is up-regulated both at basal and $\mathrm{H}_{2} \mathrm{O}_{2}$-induced conditions (Figure 5B).

To find out whether the elevated thioredoxin is responsible for the reduced ROS level and the subsequent inhibition of EMT response upon SOCS1 transduction, we have examined the effect of thioredoxin ablation by shTrx transduction into HA-SOCS1 cells. The result
A

\begin{tabular}{|c|c|c|c|c|c|c|}
\hline & \multicolumn{3}{|c|}{ HA } & \multicolumn{3}{|c|}{ HA-SOCS1 } \\
\hline $\mathrm{H}_{2} \mathrm{O}_{2}$ & - & + & + & - & + & + \\
\hline NAC & - & - & + & - & - & + \\
\hline SOCS1 & \multicolumn{6}{|c|}{$-\cdots-$} \\
\hline Vimentin & \multicolumn{6}{|c|}{---} \\
\hline Snail & \multicolumn{6}{|c|}{ 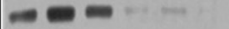 } \\
\hline E-Cad & \multicolumn{6}{|c|}{ (9) } \\
\hline$\beta$-Actin & \multicolumn{6}{|c|}{$1-\infty-\infty=$} \\
\hline
\end{tabular}
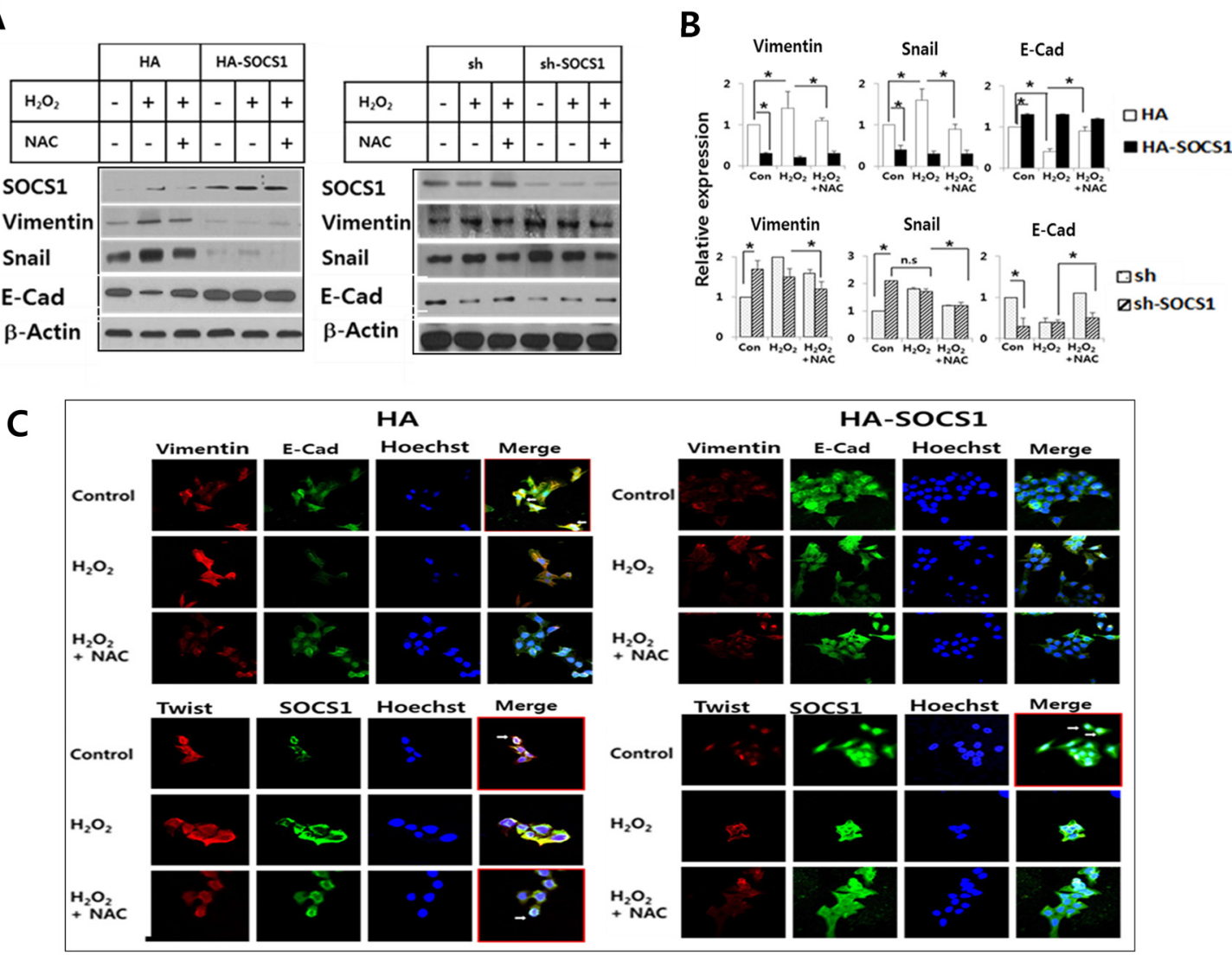

Figure 2: Anti-EMT function of SOCS1: EMT markers were down-regulated in cells transduced with SOCS1, while promoted upon SOCS1 knock-down. HA \& HA-SOCS1, and sh \& sh-SOCS1 HCT116 p53+/+ cells were established by transfection of respective vectors by electroporation as described in Materials and Methods. Cells maintained in the selection media were treated with $\mathrm{H}_{2} \mathrm{O}_{2}(300 \mu \mathrm{M}$ for $2 \mathrm{~h}$ ) and changes in EMT markers were analyzed by immunoblotting. A representative blot is shown for each cell system A. Densitometric analysis of immunoblots normalized to beta-actin showing relative expression of EMT regulators. Data represent mean+SE obtained from 3 independent experiments B. HCT116 p53 +/+ HA \& HA-SOCS1 cells were treated with $\mathrm{H}_{2} \mathrm{O}_{2}$ as above and then changes in EMT markers and SOCS1 location were examined by immunofluorescence analysis C. Vimentin and E-cadherin colocalize at the cell membrane in control HA cells shown in the merged figure (white arrows in upper left panel). SOCS1 colocalizes with Twist in the perinuclear region (Lower left panel). In SOCS1-transduced cells E-cadherin expression levels increased over vimentin (Upper right panel), and SOCS1 expression was seen both in the cytosol and nucleus with reduced Twist expression (Lower right panel). 
demonstrates that shTrx transduction abrogated the SOCS1-induced anti-EMT effect, as shown by restoration of Snail expression with suppression of E-cadherin levels (Figure 5C). Such reversal in EMT response was correlated well with restored ROS levels in HA-SOCS1 cells upon shTrx transduction (Figure 5D). The ROSinduced activations of Src and Jak were also recovered by thioredoxin ablation in HA-SOCS1 cells (Figure 5C). Together these data strongly suggest that SOCS1-induced ROS down-regulation and EMT inhibition occur through thioredoxin up-regulation.

\section{Role of Src inhibition in thioredoxin up- regulation by SOCS1}

In order to elucidate the mechanisms for the reciprocal regulation of thioredoxin and ROS by SOCS1 to attenuate EMT in colon cancer cells, we have investigated the function of Src as a mediator of SOCS1 action. Src has been implicated in both ROS production and regulation of antioxidant factors [19, 38, 39]. In particular, Src is shown to participate in ROS generation through the activation of the Nox system [19]. On the other hand, Src family enzyme-induced tyrosine phosphorylation of Nrf-2 is shown to be required for its nuclear export, which serves as a mechanism inhibiting Nrf-2 activity, an anti-oxidant transcription factor [38]. Thus, the effect of Src ablation on the $\mathrm{H}_{2} \mathrm{O}_{2}$-induced intracellular ROS was examined. As shown in Figure 6A, shSrc transduction significantly reduced intracellular ROS levels induced upon $\mathrm{H}_{2} \mathrm{O}_{2}$ stimulation. More importantly, while shSOCS1 cells displayed enhanced ROS levels at both basal and oxidanttreated conditions, Src ablation negated the shSOCS1induced up-regulation of ROS (Figure 6B). In correlation with this, elevation of thioredoxin expression was evident upon shSrc transduction. It should be noted that shSOCS1 caused reduced thioredoxin level with enhanced Src activity and EMT markers, which were all reversed by Src ablation with shSrc (Figure 6C). In mock (sh) cells, shSrc transduction up-regulated both total and nuclear Nrf-2 while reducing cytosolic Nrf-2. In shSOCS1 cells such phenomena were reversed which were in turn, mostly recovered by shSrc: shSOCS1-induced decrease in nuclear

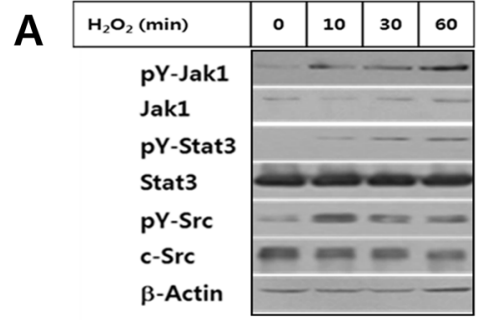

B

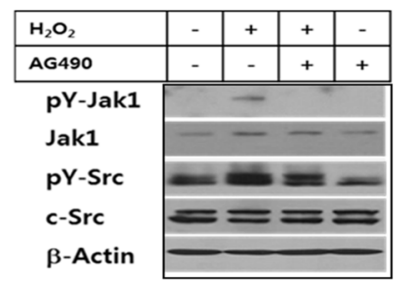

C

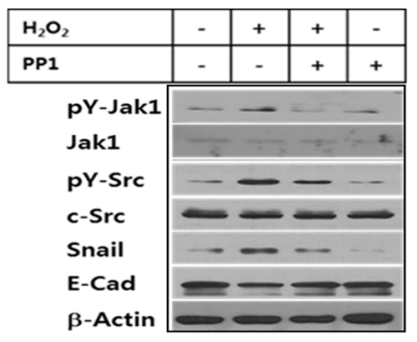

D

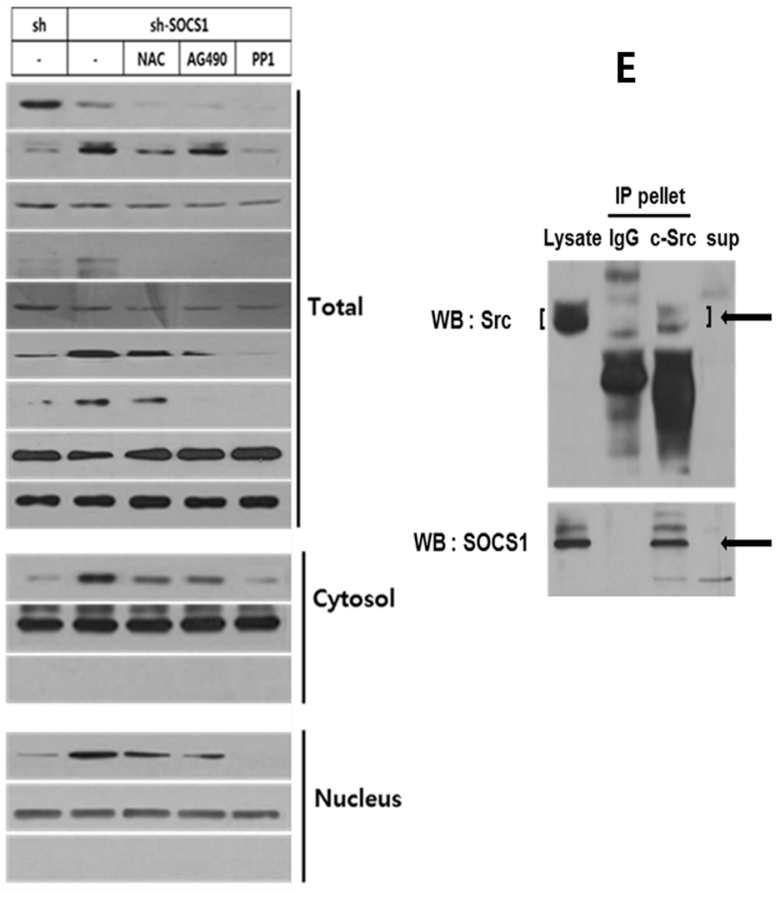

Figure 3: ROS-induced Jak and Src participate in EMT signaling, which are regulated by SOCS1. HCT116 p53 +/+ cells were treated with $\mathrm{H}_{2} \mathrm{O}_{2}$ at $200 \mu \mathrm{M}$ for different durations and analyzed for Jak and Src activation by Western blot A. HCT116 p53 +/+ cells were treated with $\mathrm{H}_{2} \mathrm{O}_{2}$ at $200 \mu \mathrm{M}$ for $2 \mathrm{~h}$ with or without pretreatment of JAK-inhibitor AG490 B., or Src-inhibitor PP1 C. and changes in EMT markers and kinases were analyzed. HCT116 p53 +/+ sh \& sh-SOCS1 cells were incubated in the absence or presence NAC, AG490 and PP1. Changes in EMT associated proteins or kinase were analyzed by Western blot D. To examine the molecular interaction of Src and SOCS1, HCT116 p53+/+ cells over-expressing SOCS1 were subject to co-immunoprecipitation assay. Cell lysates were incubated with rabbit monoclonal c-Src Ab or control rabbit IgG followed by protein A/G-agarose beads. The immunoprecipitated pellets were separated from the supernatant, which were resolved on SDS-PAGE along with total lysates, and subjected to immunoblotting to reveal SOCS1 and Src protein bands E. 


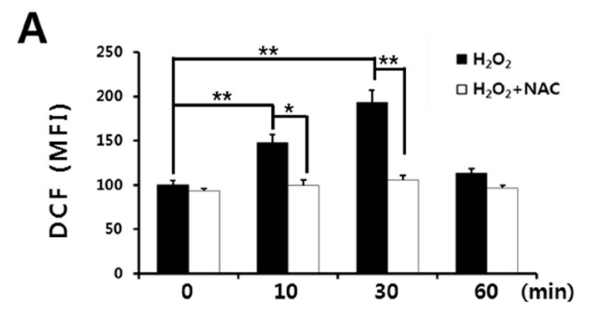

B

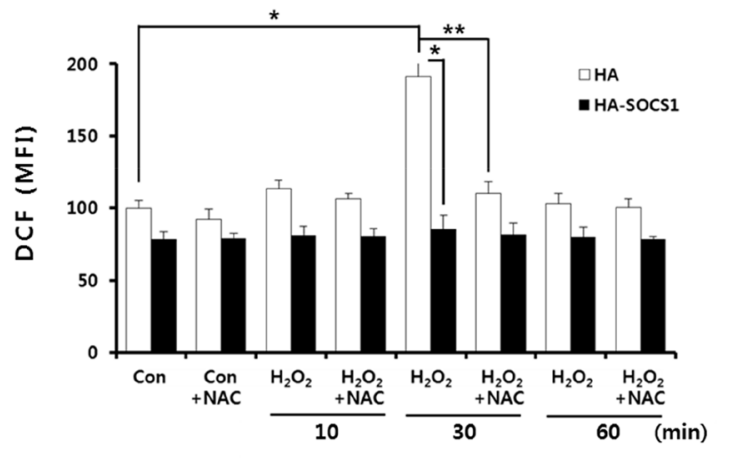

C

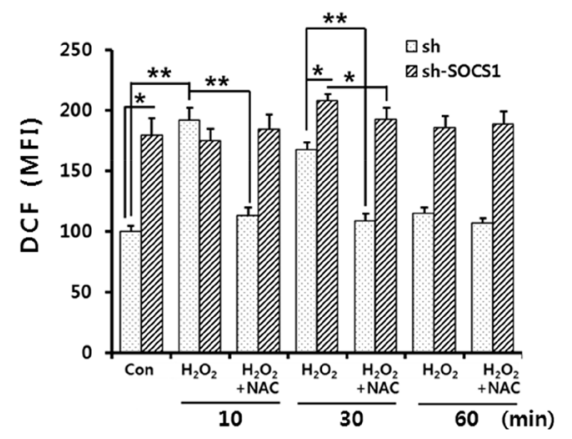

Figure 4: ROS suppressive function of SOCS1 as revealed by analysis of intracellular ROS levels upon SOCS1 or shSOCS1 transduction. Cells were stimulated with $\mathrm{H}_{2} \mathrm{O}_{2}$ in the absence or presence of NAC pretreatment for $1 \mathrm{~h} . \mathrm{H}_{2} \mathrm{O}_{2}$ treatments were done for indicated times and analysis of intracellular ROS levels was performed for parental HCT116 p53 +/+ A., HCT116 p53 +/+ HA \& HA-SOCS1 B., and sh \& sh-SOCS1 C.

A

\begin{tabular}{|c|c|c|c|c|c|}
\hline $\mathrm{H}_{2} \mathrm{O}_{2}(\mathrm{~h})$ & 0 & 1 & 2 & 4 & 8 \\
\hline Prx & - & - & - & $T$ & - \\
\hline TrxR1 & - & - & - & - & - \\
\hline Trx & & - & - & - & \\
\hline$\beta$-Actin & - & - & - & - & - \\
\hline
\end{tabular}

C

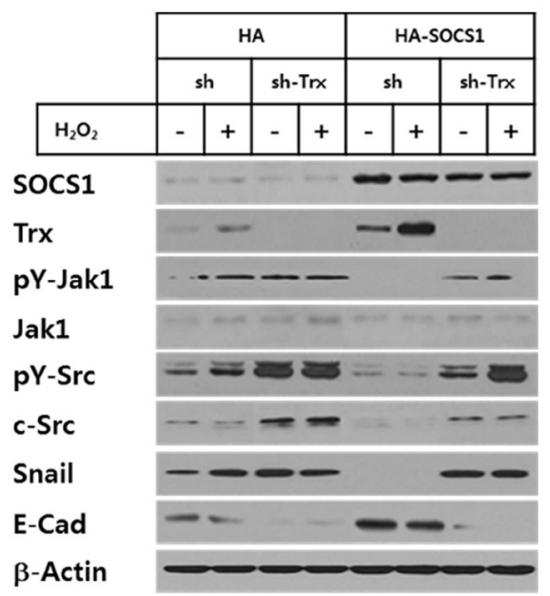

B

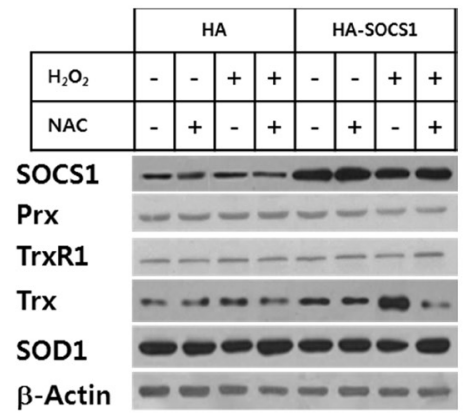

D

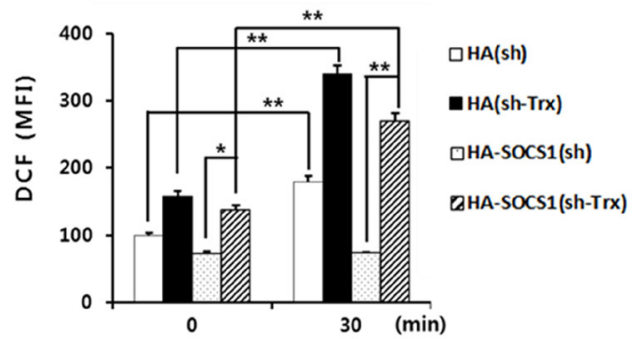

Figure 5: Role of thioredoxin induction by SOCS1 in down-regulation of ROS-mediated EMT signaling. HCT116 p53 +/+ cells A. and HCT116 p53 +/+ HA \& HA-SOCS1 cells B. were treated with $\mathrm{H}_{2} \mathrm{O}_{2}$ for different durations and antioxidant proteins were analyzed by Western blot. HA \& HA-SOCS1 cells were each transfected with shRNA or shTrx and then treated by $\mathrm{H}_{2} \mathrm{O}_{2}$, after which changes in EMT markers and kinases were analyzed by Western blot at $2 \mathrm{~h} \mathbf{C}$. Analysis of intracellular ROS levels was performed for cells in Panel (C) at 30 min after $\mathrm{H}_{2} \mathrm{O}_{2}$ treatment D. 
Nrf-2 is restored by shSrc to correlate with the substantial levels of thioredoxin expression (Figure 6C).

The data demonstrate that the increase of ROS levels caused by shSOCS1 is dependent on Src. To confirm the function of Src activity in nuclear vs cytosolic retention of Nrf-2, the effect of PP1 was analyzed (Figure 7). Similar to the case of Src knock-down, the inhibition of Src activity by PP1 resulted in up-regulation of nuclear Nrf-2 at the expense of decrease in cytosolic Nrf-2 (Figure 7A, lanes 5 and 6). PP1-treated cells exhibited increased thioredoxin expression with a significant reduction of intracellular ROS levels upon $\mathrm{H}_{2} \mathrm{O}_{2}$ treatment (Figure 7A and 7C). As compared to PP1, Jak inhibitor AG490 has little effects on the suppression of ROS level and Nrf-2 translocation under $\mathrm{H}_{2} \mathrm{O}_{2}$ treatment. Nuclear to cytosolic ratio of Nrf-2 was notably increased by PP1 but not by AG490 (Figure 7B). Together the data suggest that Src plays a negative role in Nrf-2-mediated anti-oxidant response such as induction of thioredoxin. Although Jak is an important target of SOCS1, inhibition of Src activity by SOCS1 appears primarily responsible for nuclear retention of Nrf-2 leading to thioredoxin expression. The enhanced ROS levels and pro-EMT signaling observed in shSOCS1 cell thus likely to be resulted from increased Src activity which induces down-regulation of thioredoxin.

\section{Anti-invasive effect of SOCS1 through ROS regulation}

The above data indicated that SOCS1 may prevent EMT signaling and response by activating the cellular anti-oxidant system. Because multiple factors involved in EMT are correlated with invasive property of tumor cells, we have examined the effect of SOCS1 in invasion capacity of HCT116 cells and the role of ROS in this process. The invasion assay was performed using a Matrigel chamber for mock and SOCS1-transduced cells. The hydrogen peroxide treatment shown to induce EMT increased the number of cells migrated through the Matrigel, which was inhibited by an anti-oxidant NAC. SOCS1-transduced cells exhibited a significantly reduced invasive capacity as compared to mock cells (Figure 8A and $8 \mathrm{~B}$ ). This is not due to the difference in cell growth, as no inhibition was observed for cell proliferation upon SOCS1 over-expression during the $72 \mathrm{~h}$ assay (Figure $8 \mathrm{C}$ ). The low invasive properties of SOCS1-tansduced cells correlated with low ROS levels observed in these cells (Figure 4), suggesting that SOCS1 exhibits anti-invasive effect through down-regulation of ROS.
A

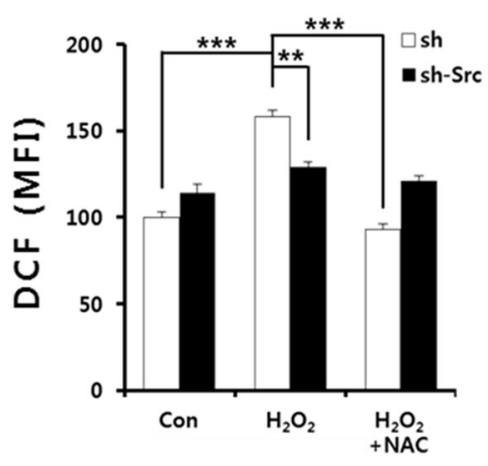

B

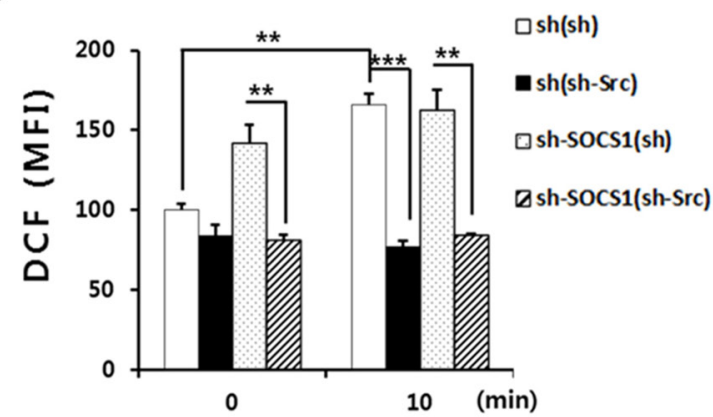

C

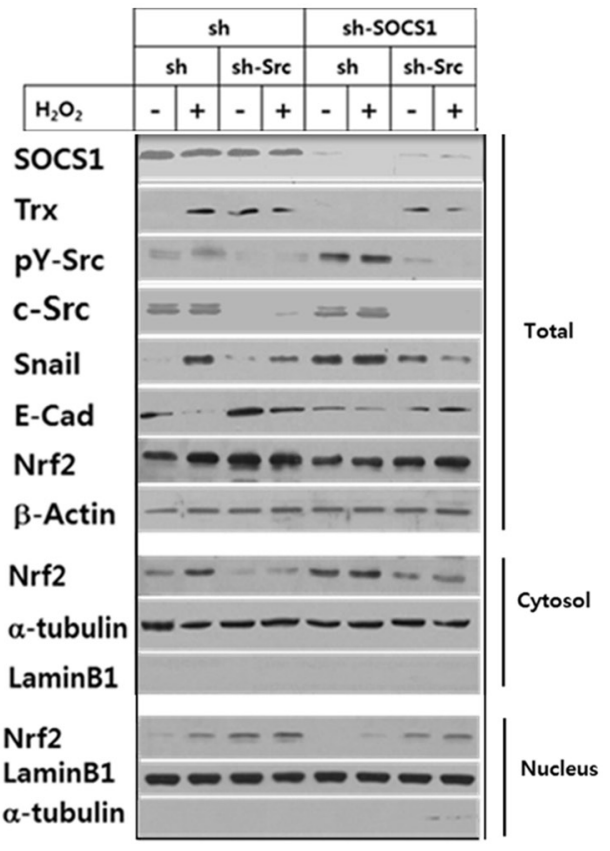

Figure 6: Role of Src in the $\mathrm{H}_{2} \mathrm{O}_{2}$-induced intracellular ROS and thioredoxin/Nrf-2 regulation by SOCS1. HCT116 p53 $+/+$ cells were transfected with sh or shSrc construct as described in the text and cells were analyzed for ROS levels upon treatment with $\mathrm{H}_{2} \mathrm{O}_{2}$ at 30 min with or without NAC pretreament A. sh and shSOCS1 cells transfected with sh or shSrc were subject to treatment with $\mathrm{H}_{2} \mathrm{O}_{2}$. The intracellular ROS levels were determined at $30 \mathrm{~min}$ B. Cells in panel B were treated with $\mathrm{H}_{2} \mathrm{O}_{2}$ for $2 \mathrm{~h}$, harvested to obtain subcellular fractions, and analyzed for the expression of thioredoxin ( $\operatorname{Trx} 1)$, Nrf-2, and EMT markers by immunoblotting $\mathbf{C}$. 


\section{DISCUSSION}

Aberrant activation and discordant regulation of Jak/STAT and SOCS pathways have been associated with different malignancy for colon cancer specimens $[30,31,40]$. Considering the potential effect of ROS generated during the therapy-induced response on cancer progression, we have investigated the anti-EMT function of SOCS1 through ROS regulation in colon cancer cells transduced with SOCS1 and shSOCS1.

Regarding the anti-EMT action of SOCS1, David et al. [41] have recently reported that SOCS1 modulates invasion and metastatic potential of SW620 colon cancer cells through up-regulation of the miRNA200 family. In this report, upon over-expression of SOCS1, SW620 cells exhibited reversal of EMT features including re-expression of E-cadherin and suppression of ZEB1. While the study suggested anti-invasive function of SOCS1 is through the induction of miRNA200 known to down-regulate ZEB1, the mechanism by which SOCS1 induces miRNA200 remains unknown leaving the upstream signaling pathways of SOCS1 action for investigation. In addition, while they have utilized highly aggressive colon cancer cells with low expression of SOCS1 for SOCS1 transduction, the effect of SOCS1 ablation was not presented.

We have chosen colon cancer cells with SOCS1 expression at intermediate levels through initial screening of various colorectal cancer cell lines (data not shown). HCT116 cells were selected since they are amenable for both SOCS1 over-expression and knock-down. Our data demonstrate that while ROS stimulation can induce EMT features in these cells, SOCS1 vs shSOCS1 transfection produces opposite features on EMT regulators which are correlated with changes in intracellular ROS levels (Figures 1, 2, 4). Furthermore the suppression of EMT signaling by SOCS1 was consistent with its blocking effect on the ROS-induced invasion as revealed by Matrigel assays (Figure 8).

The mechanism by which SOCS1 down-regulates the intracellular ROS levels was then investigated, which demonstrated that thioredoxin up-regulation by SOCS1 is a primary mode. There were no apparent changes in other anti-oxidant enzymes, such as superoxide dismutase, peroxiredoxin or thioredoxin reductase in SOCS1transduced cells. More importantly thioredoxin depletion abolished SOCS1-induced suppression of ROS, Src, Jak, p65 activity and EMT markers, suggesting that anti-ROS and anti-EMT functions of SOCS1 are mediated through thioredoxin up-regulation (Figure 5). Such anti-ROS action of SOCS1 is in line with our previous study, in which ROS-mediated apoptosis of Jurkat T cells by TNFalpha or hydrogen peroxide is inhibited by SOCS1 through thioredoxin induction [33].

\section{B}

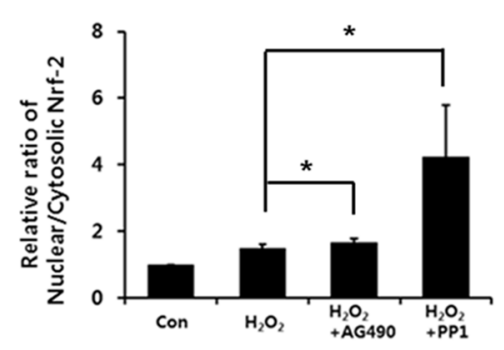

C

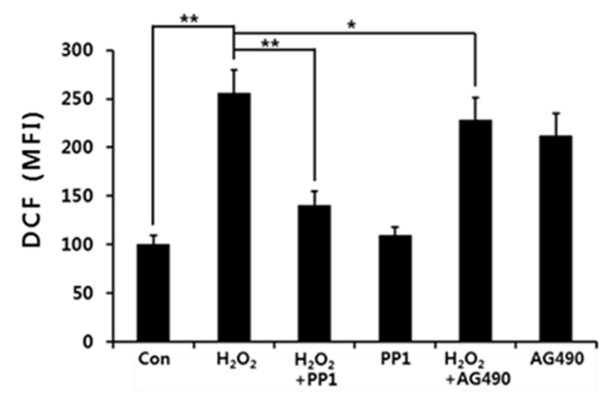

Figure 7: Src inhibitor but not Jak inhibitor induces nuclear retention of Nrf-2 and suppression of intracellular ROS levels. HCT116 p53 +/+ cells were stimulated with $\mathrm{H}_{2} \mathrm{O}_{2}$ at $200 \mu \mathrm{M}$ for $2 \mathrm{~h}$ with or without PP1 or AG490 treatment. Cell lysates were analyzed for Src, Jak, and Trx. Nrf-2 levels were further analyzed in total, cytosolic and nuclear preparations A. Nuclear to cytosolic ratio of Nrf-2 was determined from densitometry analysis of blots with cells treated with PP1 or AG490 prior to $\mathrm{H}_{2} \mathrm{O}_{2}$ stimulation B. Intracellular ROS levels were measured at 30 min post $\mathrm{H}_{2} \mathrm{O}_{2}$ stimulation C. Data in (B) and (C) represent mean $+\mathrm{SE}$ from 3 independent sets of experiments. 
In the present work we have further examined the mechanism of thioredoxin regulation by SOCS1 and obtained data indicating that inhibition of Src activity is responsible for the promotion of thioredoxin expression through nuclear retention of Nrf-2. Nrf-2 is a transcription factor critical for the induction of anti-oxidant enzymes by binding to the anti-oxidant response element of promoters for HO-1, SOD1 and thioredoxin [39, 42, 43]. The finding that Src family kinase Fyn activity-dependent phosphorylation of Nrf-2 is required for nuclear export $[38,39]$ provides an explanation for the increase in nuclear Nrf-2 levels upon Src inhibition (Figure 7A). As Src activity is reciprocally regulated by SOCS1 and ShSOCS1, increased Src activity in shSOCS1 cells can be responsible for decreased nuclear Nrf-2 levels as compared to mock cells (Figure 6C).

Although both Jak and Src are regulated by SOCS1, Src appears to act upstream of Jak and to be a dominant target of SOCS1 to down-regulate ROS signal in colon cancer cells. PP1 but not AG490 promoted nuclear retention of Nrf-2 with thioredoxin induction and suppressed intracellular ROS levels upon $\mathrm{H}_{2} \mathrm{O}_{2}$ treatment (Figure 7). It should be noted that among various antioxidant factors, thioredoxin is a primary enzyme upregulated upon SOCS1 over-expression and Src ablation (Figure 5B and Supplementary Figure S2). Thioredoxin is also shown to bind and protect protein tyrosine phosphatases (PTP) from the ROS-induced inactivation thus attenuating Jak activity [33, 44]. Hence thioredoxin up-regulated in SOCS1-transduced HCT116 cells, may further inhibit Src and Jak by maintaining PTP activities.

Tumor cells often exhibit high intracellular ROS levels due to increased metabolism and adapt to the oxidative stress caused by exogenous ROS produced in inflammatory tumor environment [45]. In addition, increased ROS production by Nox system activated by oncogenic pathways such as Src [19] would also contribute to EMT. In this regard, SOCS1 may inhibit ROS-mediated EMT process by down-regulation of ROS as well as Src activity. The molecular interaction noted
A
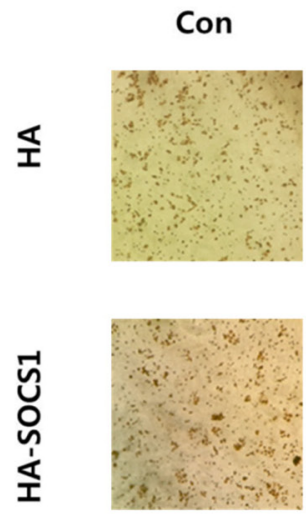

$\mathrm{H}_{2} \mathrm{O}_{2}$
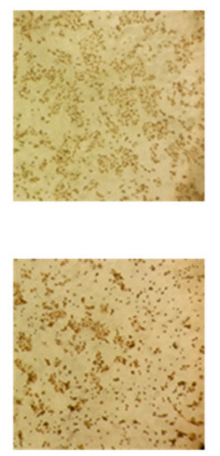

$\mathrm{H}_{2} \mathrm{O}_{2}+\mathrm{NAC}$
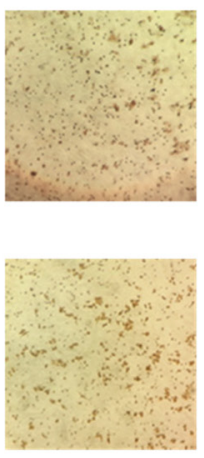

B
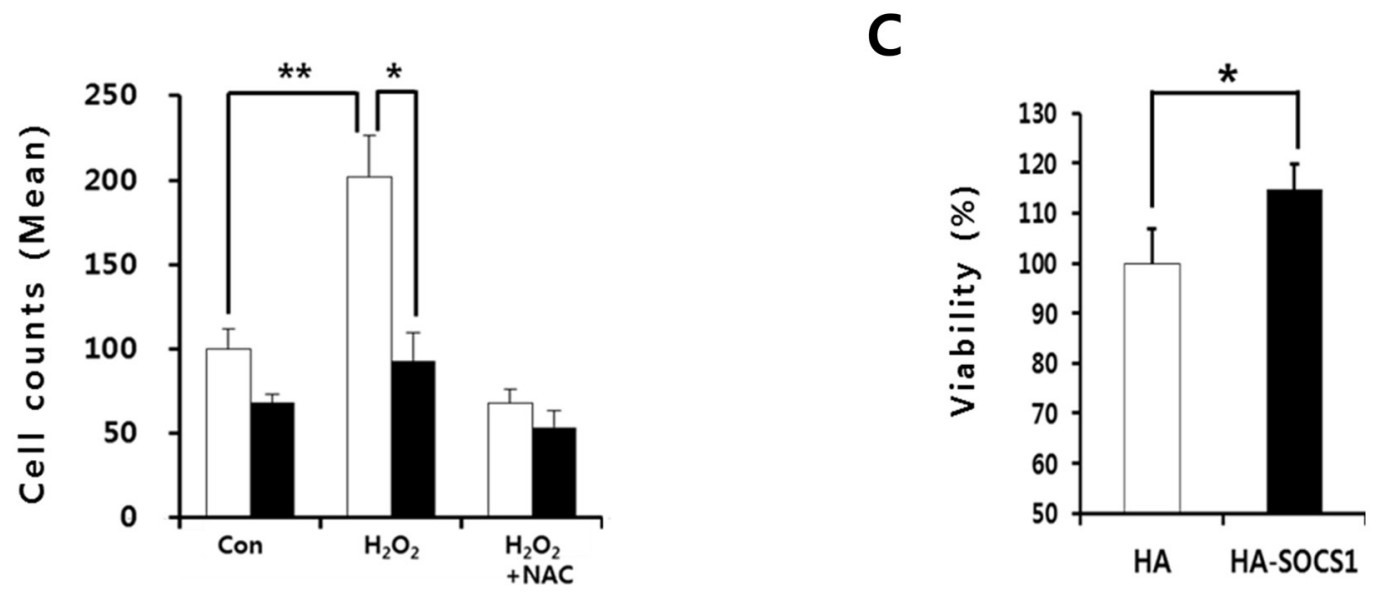

Figure 8: Inhibitory effects of SOCS1 on the $\mathrm{H}_{2} \mathrm{O}_{2}$-mediated invasiveness of the HCT116 colon cancer cells. HCT116 HA \& HA-SOCS1 cells were treated with $\mathrm{H}_{2} \mathrm{O}_{2}$ in the presence or absence of NAC pretreatment and the invasive properties were assessed by Matrigel assays as described in the text. Cells were stained with Hematoxylin A. and counted cell numbers are shown as mean+SE in bar graphs B. HCT116 HA \& HA-SOCS1 cells were grown for $72 \mathrm{~h}$ and then examined for viability using MTT assays C. 
between Src and SOCS1 suggest a possible mode of Src kinase inhibition by SOCS1 (Figure 3E). While SOCS1 is known to cause proteolytic degradation of tyrosinephosphorylated substrates upon binding, the degradation of c-Src by SOCS1 was not noted in HA-SOCS1 cells (Supplementary Figure S3). Thus, the activity regulation rather than degradation of Src appears responsible for the attenuation of downstream signaling for EMT. In addition to the decreased Src activity, the SOCS-box mediated degradation of signaling molecules such as NF- $\kappa \mathrm{B} / \mathrm{p} 65$ may also aid the anti-EMT function of SOCS1 $[32,46]$.

In summary, we have shown that ROS signal potentially induces EMT in colon cancer cells through Src activation and that SOCS1-induced inhibition of Src activity leads to the up-regulation of thioredoxin via Nrf-2, thereby inhibiting EMT. Down-regulation of ROS by SOCS1 can be resulted from both the inhibition of Src-mediated Nox activity [19] and the promotion of thioredoxin-mediated ROS scavenging activities [47]. Thus SOCS1 is likely to participate in the ROS regulatory loop involving Src and thioredoxin (summarized in Figure 9). By reducing intracellular ROS found at abnormally high levels in cancer cells, SOCS1 may exert antiEMT and anti-invasive functions to prevent malignant progression. Such tumor suppressive functions of SOCS1 through the activation of cellular anti-oxidant defense system would be particularly useful in control of colon cancers surviving high oxidative stress induced upon chemo- or radiation therapy.

\section{MATERIALS AND METHODS}

\section{Antibodies}

Anti-Snail, anti-E-Cadherin, anti-N-Cadherin, antiSlug, anti-peroxiredoxin(Prx), anti-thioredoxin(Trx1), anti-phosphotyrosine(Y416)-Src, anti-phospho-Erk1/2, anti-phosphotyrosine-Jak1, anti-phosphotyrosine-Stat1, and anti-tubulin Abs were from Cell Signaling Technology (Beverley, MA). Anti-SOCS1, anti-vimentin1, antiTrxR1, and anti-SOD1 Abs were purchased from Santa Cruz Biotechnology (Santa Cruz, CA). Anti-p65 Ab was from Upstate Biochemicals (Charlottesville, VA). Anti-LaminB1 and anti-c-Src Abs were from Abcam (Cambridge, MA).

\section{Cell culture}

Human colon cancer cell lines HCT116 p53 +/+ (p53 wt), HCT116 p53 -/- (p53 null) and HT29 (p53 $\mathrm{mt}$ ) were obtained from the American Type Culture Collection. Cells were cultured in complete DMEM supplemented with 10\% FBS (Invitrogen, Carlsbad, CA), 10 mM HEPES, 2 mM L-glutamine, $50 \mu \mathrm{M}$ 2-ME, 10,000 $\mathrm{U} / \mathrm{ml}$ penicillin, and $10,000 \mu \mathrm{g} / \mathrm{ml}$ streptomycin (Life Technologies, Grand Island, NY) at $37^{\circ} \mathrm{C}$ under $5 \% \mathrm{CO}_{2}$. HA \& HA-SOCS1/HCT116 p53 +/+ cells were cultured and maintained with $200 \mu \mathrm{g} / \mathrm{ml} \mathrm{G} 418$ (Sigma-Aldrich). Sh \& sh-SOCS1/HCT116 p53 +/+ cells were maintained with $100 \mathrm{ng} / \mathrm{ml}$ puromycin (Sigma-Aldrich). shSrc-transfected sh-SOCS1/HCT116 or shTrx-transfected HA-SOCS1 cells

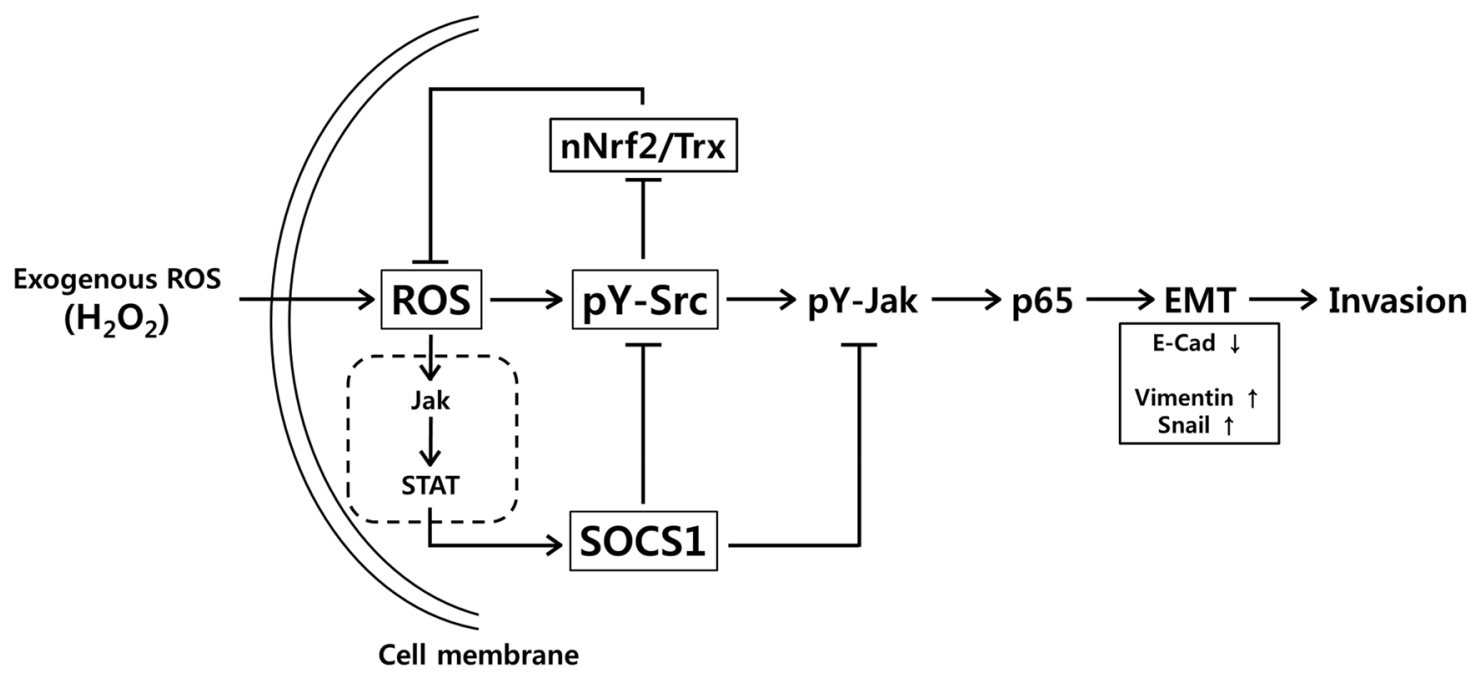

Figure 9: Model for the mechanism of SOCS1 action in inhibition of EMT signaling through ROS suppression involving Src-mediated thioredoxin regulation in colon cancer cells. In HCT116 cells, intracellular ROS generated upon exogenous hydrogen peroxide treatment stimulates Src and Jak kinase activation leading to p65 activation and modulation of EMT regulators such as up-regulation of vimentin and Snail accompanied with down-regulation of E-Cadherin. SOCS1 induced by ROS signal suppresses Src activity involving molecular interaction. The pY-Src activity is responsible for attenuation of nuclear Nrf-2 (nNrf-2) and thioredoxin (Trx) levels. Src inhibition by SOCS1, thus results in increased Trx and decreased ROS levels in SOCS1-transduced cells. Src inactivation leads to the reduced EMT signaling and invasion property. Jak inhibition during this process can be achieved directly by SOCS1 and via suppression of Src by SOCS1. 
were maintained with puromycin or G418 plus puromycin, respectively. Cells were cultured in a humidified $5 \% \mathrm{CO}_{2}$ incubator at $37^{\circ} \mathrm{C}$.

\section{Hydrogen peroxide and inhibitor treatments}

Cells were treated with hydrogen peroxide $\left(\mathrm{H}_{2} \mathrm{O}_{2}\right.$, Mpbio) at different doses and durations. For optimal induction of EMT markers, the parental HCT116 cells were treated with $200 \mu \mathrm{M} \mathrm{H} \mathrm{H}_{2}$, whereas $\mathrm{HA}$ or sh vector-transfected cells were treated with $300 \mu \mathrm{M} \mathrm{H}_{2} \mathrm{O}_{2}$, unless otherwise indicated. Treatment with inhibitors (NAC, AG490, and PP1: Sigma Aldrich) was done prior to cellular stimulation with hydrogen peroxide. NAC and AG490 were treated at $10 \mathrm{mM}$ and $100 \mu \mathrm{M}$ for $1 \mathrm{~h}$, respectively. PP1 was at $5 \mu \mathrm{M}$ for $4 \mathrm{~h}$.

\section{Gene transfection}

HA \& HA-SOCS1, sh \& sh-SOCS1, and shTrx1 constructs were previously described [33]. The shSrc constructs were obtained from Sigma Aldrich (NM 198291.1 CCGGGTCATGAAGAAGCTGAGGCATCTCGAGATG CCTCAGCTTCTTCATGACTTTTTG). For transfection, HCT116 cells in $500 \mu$ Opti-MEM buffer (Invitrogen) were mixed with $5 \mu \mathrm{g}$ each of pcDNA-HA, HA-SOCS1, shRNA vectors and shRNA against SOCS1, Src and Trx. The cell mixture was transferred into a $4 \mathrm{~mm}$ electrode gap cuvette and transfection was performed using Gene Pulser X cell electroporation system (Bio-Rad, Herbercules, CA).

\section{Immunofluorescence analysis}

Fix-permeabilized cells were stained with primary antibodies (E-Cadherin, Twist1, vimentin, and SOCS1), followed by incubation with fluorescence-conjugated secondary antibodies (Alexa-488, Alexa-594: Molecular probe, Eugene, OR, USA and TRITC: Biofixs, Tampere, Finland). Nuclear staining was performed with Hoechst 33342 (Molecular probe). After extensive washing, cells were analyzed by using a confocal microscope (LSM 710 Meta DuoScan, Carl Zeiss Micro Imaging GmbH, Germany) equipped with a $40 \mathrm{X}$ objective.

\section{MTT assays}

Cell viability was determined with a colorimetric MTT assay using 3-[4,5-Dimethylthiazol-2-y]-2,5diphenyltetrazolium bromide (Promega).

\section{Analysis of intracellular ROS levels by FACS}

Cells were stained with $1 \mu \mathrm{M} \mathrm{H}_{2} \mathrm{DCF}-\mathrm{DA} 20 \mathrm{~min}$ before the end of the incubation with hydrogen peroxide. Fluorescence was measured with excitation at $480 \mathrm{~nm}$ and emission at $530 \mathrm{~nm}$ to assess intracellular ROS levels using the FACS Calibur flow cytometry system equipped with CELLQuestpro software (BD Bioscience).

\section{In vitro invasion assay}

An in vitro invasion assay was performed using a Matrigel kit (Chemicon), according to the manufacturer's protocol. Invasiveness was evaluated by staining cells that had migrated through the extracellular matrix layer and adhered to the polycarbonate membrane at the bottom of the insert during the 48 to $72 \mathrm{~h}$ assays. Numbers of cells adhering to different regions of the bottom of the insert were counted at $200 \mathrm{X}$ magnification.

\section{Western blot analysis and co- immunoprecipitation assay}

Whole cell, cytosolic, or nuclear lysates were isolated as previously described [32]. The lysates (60 $\mu \mathrm{g}$ each) were separated on SDS-PAGE and transferred to polyvinylidene difluoride membranes. After incubation with primary Abs, the immunoblots were revealed by HRP-conjugated anti-mouse, anti-rabbit or anti-rat secondary Abs (Cell Signaling Technologies and Santa Cruz) and detection with Immobilon Western (Millipore, Billerica, MA). For immunoprecipitation, cell extracts were prepared in immunoprecipitation buffer $(10 \mathrm{mM}$ HEPES [pH 7.6], $15 \mathrm{mM} \mathrm{KCl,} 2 \mathrm{mM} \mathrm{MgCl}, 0.1 \%$ Nonidet P-40, $1 \mathrm{mM}$ PMSF) and complete protease inhibitor (Roche). The extracts $(600 \mu \mathrm{g}$ proteins) were incubated with rabbit monoclonal anti-Src $\mathrm{Ab}(\mathrm{Abcam})$ or rabbit IgG for $12 \mathrm{~h}$ at $4^{\circ} \mathrm{C}$. Protein $\mathrm{A} / \mathrm{G}$-agarose beads (Santa Cruz Biotechnology) were then added, after which the bound proteins were released, resolved on SDS-PAGE, and analyzed by immunoblotting.

\section{Densitometry analysis}

The densitometric analysis of immunoblots was performed using ImageJ software.

\section{Statistical analysis}

All experiments were performed at least in three independent sets. The values are presented as means \pm SE. Statistical significance was determined by a Student-t-test. A value of $* \mathrm{p}<0.05, * * \mathrm{p}<0.01$ and $* * * \mathrm{p}<0.001$ was considered statistically significant.

\section{ACKNOWLEDGMENTS}

This study is supported by National Research Foundation of Korea; \#2012R1A2A2A01015258, \#2013M2B2A9A03051275, \#2015003291, \#2015022926, \#2016911262. 


\section{CONFLICTS OF INTEREST}

The authors declare no conflicts of interest.

\section{REFERENCES}

1. Michael S, Navdeep S. ROS links glucose metabolism to breast cancer stem cell and EMT phenotype. Cell. 2013; 3:265-267.

2. Cardin R, Piciocchi M, Bortolami M, Kotsafti A, Barzon L, Lavezzo E, Sinigaglia A, Rodriguez-Castro KI, Rugge M, Farinati F. Oxidative damage in the progression of chronic liver disease to hepatocellular carcinoma: An intricate pathway. World journal of gastroenterology. 2014; 20:3074-3086.

3. Sreevalsan S, Safe S. Reactive oxygen species and colorectal cancer. Current colorectal cancer reports. 2013; 9:350-357.

4. Hiraga R, Kato M, Miyagawa S, Kamata T. Nox4-derived ROS signaling contributes to TGF-beta-induced epithelialmedenchymal transition in pancreatic cancer cells. Anticancer research. 213; 33:4431-4438.

5. Radisky DC, Levy DD, Littlepage LE, Liu H, Nelson CM, Fata JE, Leake D, Godden EL, Albertson DG, Nieto MA, Werb Z, Bissell MJ. Rac1b and reactive oxygen species mediate MMP-3-induced EMT and genomic instability. Nature. 2005; 7047:123-127.

6. Kalluri R, Weinberg RA. The basics of EMT. Journal of clinical invsestigations. 2009; 119:1420.

7. Thiery JP, Sleeman JP. Complex networks orchestrate epithelial-mesenchymal transitions. Molecular and cellular biology. 2006; 7:131-142.

8. Nieto MA. The snail superfamily of zinc-finger transcription factors. Molecular and cellular biology. 2002; 3:155-166.

9. Yang J, Mani SA, Donaher JL, Ramaswamy S, Itzykson RA, Come C. Twist, a master regulator of morphogenesis, plays an essential role in tumor metastasis. Cell. 2004; 117:927-939.

10. Peinado H, Olmeda D, Cano A. Snail, Zeb and bHLH factors in tumour progression: an alliance against the epithelial phenotype? Nature reviews cancer. 2007; $7: 415-428$.

11. Sheehan KM, Gulmann C, Eichler GS, Weinstein JN, Barrett HL, Kay EW, Conroy RM, Liotta LA, Petricoin EF. Signal pathway profiling of epithelial and stromal compartments of colonic carcinoma reveals epithelialmesenchymal transition. Oncogene. 2008; 3:323-331.

12. Shimojo Y, Akimoto M, Hisanaga T, Tanaka T, Tajima Y, Honma Y, Takenaga K. Attenuation of reactive oxygen species by antioxidants suppresses hypoxia-induced epitheluial-mesenchymal transition and metastasis of pancreatic cancer cells. Clinical and experimental metastasis. 2013; 30:143-154.
13. Magdalena A, Derek C. ROS-induced epithelial-mesenchymal

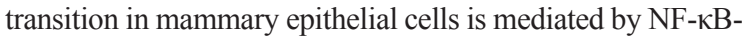
dependent activation of Snail. Oncotarget. 2014; 9:2827-2838. doi: 10.18632/oncotarget.1940.

14. Shinohara M, Adachi Y, Mitsushita J, Kuwabara M, Nagasawa A, Harada S, Furuta S, Zhang Y, Seheli K, Miyazaki H, Kamata T. Reactive oxygen species generated by Nox 1 contributes to cell invasion by regulating MMP9 production and cell migration. Journal of biological chemistry. 2010; 285:4481-4488.

15. Liu F, Gomez GAM, Meyskens FL Jr. NADPH oxidase1 overexpression enhances invasion via MMP2 and EMT in melanoma cells. Journal of investigative dermatology. 2012; 132:2033-2041.

16. Park CM, Park MJ, Kwak HJ, Lee HC, Lee SH, Park IC, Rhee $\mathrm{CH}$, Hong SI. Ionizing radiation enhances matrix metalloproteinase- 2 secretion and invasion of glioma cells through Src/epifermal growth factor receptor-mediated p38/Akt and phosphatidylinositol 3-kinase/Akt signaling pathways. Cancer research. 2006; 66:8511-8519.

17. Sirvent A, Benistant C, Pennequin J, Veracini L, Simon V, Bourgaux JE, Hollande F, Cruzalegui F, Roche S. Src family tyrosine kinase-driven colon cancer cell invasion is induced by Csk membrane delocalization. Oncogene. 2010; 29:1303-1315.

18. Lui W, Yue F, Zheng M, Merlot AM, Bae DH, Huang M, Lane D, Jansson P, Lui GY, Richardson V, Sahni S, Kalinowski D, Kavacevic Z, Ricardson DR. The protooncogene c-Src and its downstream signaling pathways are inhibited by the metastasis suppressor NDRG1. Oncotarget. 2015; 6:88518874. doi: 10.18632/oncotarget.3316.

19. Gianni D, Bohl B, Courtneidge SA, Bokoch GM. The involvement of the tyrosin kinase c-Src in the regulation of reactive oxygen species generation mediated by NADPH oxidase-1. Molecular and cellular biology. 2008; 19:2984-2994.

20. Alexander WS, Starr R, Fenner JE, Scott CL, Handman E, Sprigg NS, Corbin JE, Cornish AL, Darwiche R, Owczarek CM, Kay TW, Nicola NA, Hertzog PJ, Metcalf D, Hilton DJ. (1999) SOCS1 is a critical inhibitor of interferon gamma signaling and prevents the potentially fetal neonatal actions of this cytokine. Cell. 1999; 98:597-608.

21. Croker BA, Kiu H, Nicholson SE. SOCS regulation of the JAK/STAT signaling pathway. Seminars in cellular and developmental biology. 2008; 19:414-422.

22. Lee TL, Yeh J, Van Waes C, Chen Z. Epigenetic modification of SOCS-1 differentially regulates STAT3 activation in response to interleukin-6 receptor and epidermal growth factor receptor signaling through JAK and/or MEK in head and neck squamous cell carcinomas. Molecular cancer therapeutics. 2006; 5:8-19.

23. Shimada K, Serada S, Fujimoto M, Nomura S, Nakatsuka R, Harada E, Iwahori K, Tachibana I, Takahashi T, Kumanogoh A, Kishimoto T, Naka T. Molecular mechanism underlying the antiproliferative effect of suppressor of 
cytokine signaling-1 in non-small cell lung cancer cells. Cancer science. 2013; 104:1483-1491.

24. Gui Y, Yeganeh M, Donates YC, Tobelaim WS, Chababi W, Mayhue M, Yoshimura A, Ramanathan S, Saucier C, Ilangumaran S. Regulation of MET receptor tyrosine kinase signaling by suppressor of cytokine signaling1 in hepatocellular carcinoma. Oncogene. 2015; 34:5718-5728.

25. Choi YB, Son M, Park M, Yun Y. SOCS6 negatively regulates $\mathrm{T}$ cell activation through p56lck to proteosomal degradation. Journal of biological chemistry. 2010; 285:7271-7280.

26. Sutherland KD, Lindeman GJ, Choong DY, Wittlin S, Brentzell L, Phillips W, Campbell IG, Visvader JE. Differential hypermethylation of SOCS genes in ovarian and breast carcinomas. Oncogene. 2004; 23:7726-7733.

27. Yoshikawa H, Matsubara K, Qian GS, Jackson P, Groopman JD, Manning JE, Harris CC, Herman JG: SOCS-1, a negative regulator of the JAK/STAT pathway, is silenced by methylation in human hepatocellular carcinoma and shows growth-suppression activity. Nature genetics. 2001; 28:29-35.

28. Calabrese V, Mallette FA, Deschênes-Simard X, Ramanathan S, Gagnon J, Moores A, Ilangumaran S, Ferbeyre G. SOCS1 links cytokine signaling to p53 and senescence. Molecular cell. 2009; 36:754-767.

29. Sitko JC, Yeh B, Kim M, Zhou H, Takaesu G, Yoshimura A, McBride WH, Jewett A, Jamieson CA, Cacalano NA. SOCS3 regulates p21 expression and cell cycle arrest in response to DNA damage. Cellular signaling. 2008; 20:2221-2230.

30. Tobelaim WS, Beaurivage C, Champagne A, Pomerleau V, Simoneau A, Chababi W, Yeganeh M, Thibault P, Klinck R, Carrier JC, Ferbeyre G, Ilangumaran S, Saucier C. Tumour-promoting role of SOCS1 in colorectal cancer cells. Scientific reports. 2015; 5:14301.

31. Schultheis B, Carapeti-Marootian M, Hochhaus A, Weisser A, Goldman JM, Melo JV. SOCS2 correlates with malignancy and exerts growth-promoting effects in prostate cancer. Blood. 2002; 99:1766-1775.

32. Oh J, Kim SH, Ahn S, Lee CE. Suppressors of cytokine signaling promote Fas-induced apoptosis through downregulation of NF- $\mathrm{kB}$ and mitochondrial Bfl-1 in leukemic $\mathrm{T}$ cells. Journal of immunology. 2012; 12:5561-5571.

33. Oh J, Hur MW, Lee CE. SOCS1 protects protein tyrosine phosphatases by thioredoxin up-regulation and attenuates JAKs to suppress ROS-mediated apoptosis. Oncogene. 2009; 28:3145-3156.

34. Galliher AJ, Schiemann WP. Src phosphorylates Tyr284 in TGF-beta type II receptor and regulates TGF-beta stimulation of p38 MAPK during breast cancer cell proliferation and invasion. Cancer research. 2007; 67:3732-3758.

35. Kamizono S, Hanada T, Yasukawa H, Minoguchi S, Kato R, Minoguchi M, Hattori K, Hatakeyama S, Yada M, Morita
S, Kitamura T, Kato H, Nakayama Ki, Yoshimura A. The SOCS box of SOCS-1 accelerates ubiquitin-dependent proteolysis of TEL-JAK2. Journal of biological chemistry. 2001; 276:12530-12538.

36. Bullock AN, Rodriguez MC, Debreczeni JE, Songyang Z, Knapp S. Structure of the SOCS4-ElonginB/C complex reveals a distinct SOCS box interface and the molecular basis for SOCS-dependent EGFR degradation. Structure. 2007; 15:1493-1504.

37. Bunda S, Kommaraju K, Heir P, Ohh M. SOCS-1 mediates ubiquitylation and degradation of GM-CSF receptor. PLoS one. 2013; 8:e76370.

38. Jain AK, Jaiswal AK. Phosphorylation of tyrosine 568 controls nuclear export of Nrf2. Journal of biological chemistry. 2006; 281:12132-12142.

39. Kaspar JW, Jaiswal AK. Tyrosine phosphorylation controls nuclear export of Fyn, allowing Nrf2 activation of cytoprotective gene expression. The FASEB journal. 2011; 25:1076-1087.

40. Slattery ML, Lundgreen A, Kadlubar SA, Bondurant KL, Wolff RK. JAK/STAT/SOCS-signaling pathway and colon and rectal cancer. Molecular carcinogenesis. 2013; 52:155-166.

41. David M, Naudin C, Letourneur M, Polrot M, Renoir JM, Lazar V, Dessen P, Roche S, Bertoglio J, Pierre J. Suppressor of cytokine signaling 1 modulates invasion and metastatic potential of colorectal cancer cells. Molecular oncology. 2014; 8:942-955.

42. Anuranjani, Bala M. Concerted action of Nrf2-ARE pathway, MRN complex, HMGB1 and inflammatory cytokines: Implication in modification of radiation damage. Redox biology. 2014; 2:832-846.

43. Hawkes HJ, Karlenius TC, Tonissen KF. Regulation of the human thioredoxin gene promoter and its key substrates: a study of functional and putative regulatory elements. Biochimica biophysica acta. 2014; 1840:303-314.

44. Schwertassek U, Haque A, Krishnan N, Greiner R, Weingarten L, Dick TP, Tonks NK. Reactivation of oxidized PTP1B and PTEN by thioredoxin1. The FEBS journal. 2014; 281:3545-3558.

45. Gupta SC, Hevia D, Patchva S, Park B, Koh W, Aggarwal BB. Upsides and downsides of reactive oxygen species for cancer: the roles of reactive oxygen species in tumorigenesis, prevention, and therapy. Antioxidant and redox signal. 2012; 16:1295-1322.

46. Strebovsky J, Walker P, Lang R, Dalpke AH. Suppressor of cytokine signaling 1 limits NF- $\kappa \mathrm{B}$ signaling by decreasing p65 stability within the cell nucleus. The FASEB journal. $2011 ; 25: 863-874$.

47. Lu J, Holmgren A. The thioredoxin antioxidant system. Free radical biology \& medicine. 2014; 66:75-87. 